Control Hosp Epidemiol 1993;14:140-144.

5. Berwick DM, Godfrey AB, Roessner J. Curing Health Care, New Strategies for Quality Improvement. San Francisco, CA: Jossey-Bass; 1990.

6. Bader BS. Rediscovering Quality. Boston, MA: Bader and Associates; 1992.

7. Burnett L, Mackay M, Costaganna G, Shaw W. A model quality system for total quality management in the pathology labora- tory. Clin Biochem Rev 1993;14:47-51

8. McConnell J. The Seven Tools of TQC. 3rd ed. Manly Vale, NSW, Australia: Delaware Books; 1986.

9. Jagger J, Hunt EH, Brand-Elnaggar J, Pearson RD. Rates of needle-stick injury caused by various devices in a university hospital. N Engl J Med 1988;319:284-288.

10. Grant L, Leavenworth RS. Statistical Quality Control. 6th ed. New York, NY: McGraw-Hill; 1988.

\title{
Increase in Vancomycin-Resistant Enterococci
}

\section{by Gina Pugliese, RN, MS Medical News Editor}

The New Jersey State Department of Health (NJSDOH) recently reported the findings from the statewide hospital laboratory isolate-based surveillance system for antimicrobial-resistant bacteria. The surveillance system, initiated in 1991 and described in the July 1995 Infection Control and Hospital Epidemiology includes the 95 acutecare hospitals that are licensed by the state of New Jersey. Organisms targeted for surveillance include gram-positive cocci resistant to vancomycin, including vancomycin-resistant enterococci (VRE); methicillin-resistant Staphylococcus aureus; gram-negative rod-shaped bacteria (GNRs) resistant to imipenem; GNRs resistant to amikacin; and pneumococcal and other streptococcal isolates resistant to penicillin. A recently revised state administrative code requires hospitals to submit a monthly surveillance report form to NJSDOH.

From 1992 through 1994, the number of hospitals reporting VRE blood isolates and the number of VRE isolates increased steadily: in 1992, 33 hospitals reported 99 isolates, whereas in 1994, 54 hospitals reported 278 isolates. In addition, in 1992, hospitals in 13 of the 21 counties reported VRE isolates, compared with 20 of 21 counties in 1994.

This system uses data that are routinely collected and collated by hospital laboratories and requires few additional resources. Because this sur- veillance system is isolate-based, it does not directly measure change in the rate of infection in persons, but is used for sentinel purposes to guide further investigation. For example, early detection and geographic tracking of VRE in New Jersey through this system have facilitated collaborative efforts involving public and private sector and academic organizations to evaluate risk factors for VRE, treatment options, VRE in vitro susceptibility before clinical trials, and the effectiveness of infection control practices.

FROM: Centers for Disease Control and Prevention. Statewide surveillance for antibiotic-resistant bacteria-New Jersey. 1992-1994. MMWR 1995;44 (27):504-506. 